\title{
Formation of Nanostructured Fullerene Interlayer through Accelerated Self-Assembly and Cross-Linking of Trichlorosilane Moieties Leading to Enhanced Efficiency of Photovoltaic Cells
}

\author{
Wei-Wei Liang, Chih-Yu Chang, Yu-Ying Lai, Sheng-Wen Cheng, Huan-Hsuan Chang, Yin-Yu Lai, \\ Yen-Ju Cheng,* Chien-Lung Wang, * and Chain-Shu Hsu*
}

Department of Applied Chemistry, National Chiao Tung University, 1001 Ta Hsueh Road Hsin-Chu, 30010, Taiwan

Supporting Information

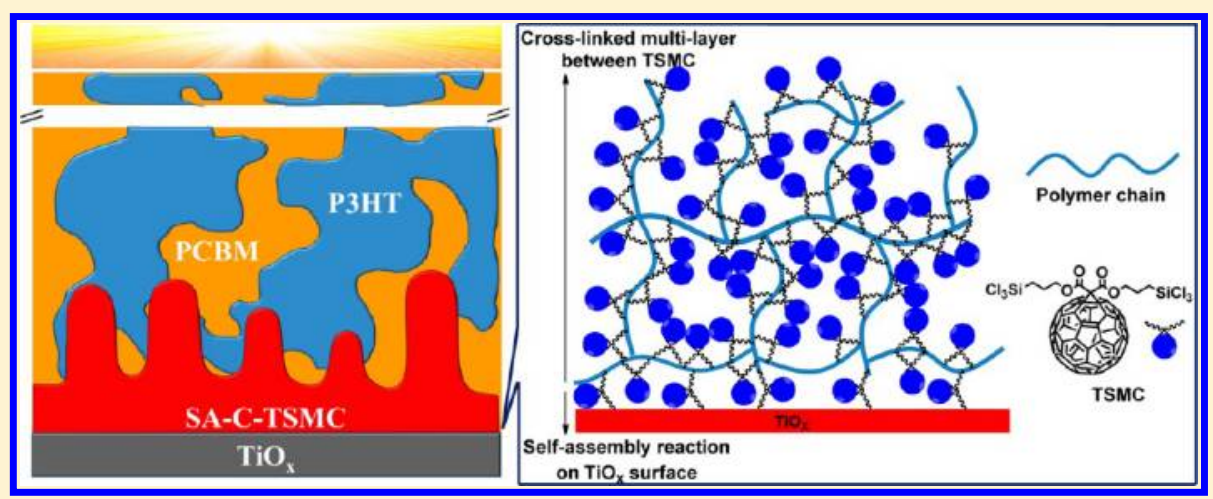

ABSTRACT: A new cross-linkable fullerene material, bis(2-(trichlorosilyl)propyl)-malonate $\mathrm{C}_{60}$ (TSMC), functionalized with two trichlorosilane groups, was easily synthesized by Pt-catalyzed olefin hydrosilylation. By making use of facile hydrolysis of the trichlorosilyl moieties, TSMC can be spontaneously self-assembled and cross-linked on the $\mathrm{TiO}_{x}$ surface by a simple spin-coating processing without the aid of photoirradiation or post-thermal treatments. The rapid formation of self-assembled and crosslinked TSMC (SA-C-TSMC) effectively passivates the residual hydroxyl groups on the $\mathrm{TiO}_{x}$ surface. More significantly, the solvent-resistant TSMC network features a nanostructured surface to provide extra charge-generating interfacial area and straight electron transport pathways. The device (ITO/ $\left.\mathrm{TiO}_{x} / \mathrm{SA}-\mathrm{C}-\mathrm{TSMC} / \mathrm{P} 3 \mathrm{HT}: \mathrm{PC}_{61} \mathrm{BM}(1: 1, \mathrm{w} / \mathrm{w}) / \mathrm{PEDOT}: \mathrm{PSS} / \mathrm{Ag}\right)$ with this $\mathrm{C}_{60}$ interlayer exhibited an efficiency of $3.9 \%$ which greatly outperformed the device without this layer. Furthermore, the strategy can also be effectively applied to the device (ITO/TiO $/$ PDITTDTBT:PC ${ }_{71} \mathrm{BM}(1: 4, \mathrm{w} / \mathrm{w}) / \mathrm{MoO}_{x} / \mathrm{Ag}$ ) incorporating a conjugated polymer, poly(diindenothiophene-alt-dithienylbenzothiadizole) copolymer (PDITTDTBT). This device delivered a high efficiency of $5.8 \%$ which represents a $35 \%$ enhancement over the device without SA-C-TSMC. This new generation of trichlorosilane-based fullerene offers an easy and accelerated processing technique to produce efficient and cost-effective inverted solar cells.

\section{INTRODUCTION}

Polymeric solar cells (PSCs) have emerged as a promising alternative technique for producing clean and renewable energy due to their potential for fabrication onto large areas of lightweight flexible substrates by low-cost solution processing. ${ }^{1-13}$ Power conversion efficiencies (PCEs) of ca. $4-5 \%$ have been obtained by using poly(3-hexylthiophene) (P3HT) and $[6,6]$-phenyl- $\mathrm{C}_{61}$-butyric acid methyl ester $\left(\mathrm{PC}_{61} \mathrm{BM}\right)$ as the photoactive materials. Besides achieving high performance, long-term stability is a growing concern. Exposure to ambient conditions rapidly degrades the efficiency of unencapsulated conventional devices due to oxidation of low-work-function $\mathrm{Al}$ cathode, or etching of ITO by acidic PEDOT:PSS layer. ${ }^{14-17}$ Air-stable $\mathrm{Ag}$ can substitutes for air-sensitive $\mathrm{Al}$ as the anodic electrode for hole collection by reversing the direction of charge collection in a regular cell. In such an inverted configuration, it is generally necessary to insert an inorganic metal oxide such as $\mathrm{TiO}_{x}$ or $\mathrm{ZnO}$ between ITO and an active layer to function as an electron-selective contact. ${ }^{18-22}$ However, due to the unfavorable energetic and incompatible interfaces, the performance of inverted devices based on the P3HT: $\mathrm{PC}_{61} \mathrm{BM}$ composite is inferior to that of regular solar cells. Surface hydroxyl groups on metal oxide can act as electron traps, which in turn deteriorates the electrical properties at the metal oxide/organic layer interface. ${ }^{23-25}$ Incorporating an n-type $\mathrm{C}_{60}$ interlayer between the inorganic metal oxide and the organic-based active layer has been demonstrated to improve the device performance by modulating the electronic interactions at the interfaces. ${ }^{26} \mathrm{~A}$ technical challenge is that the deposited fullerene interlayer can

Received: February 7, 2013

Revised: May 20, 2013

Published: June 10, 2013 


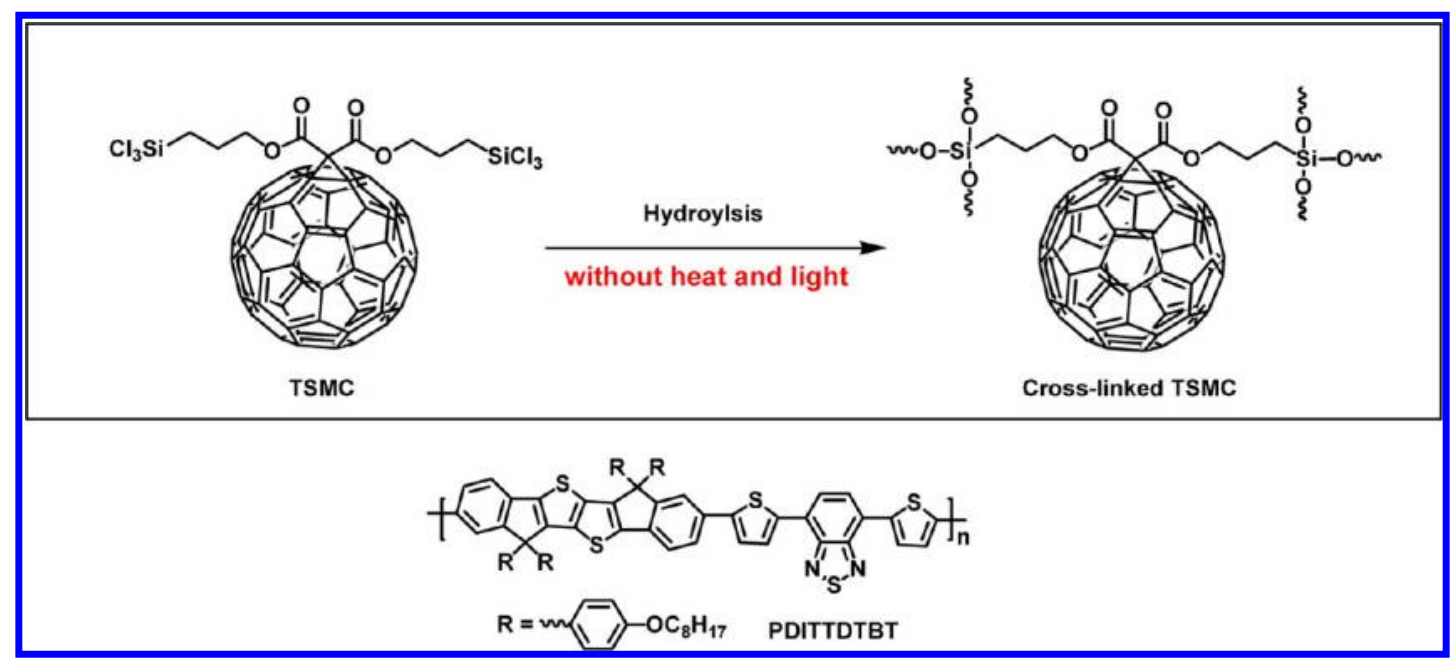

Figure 1. TSMC and its cross-linked structures, and PDITTDTBT copolymer.

Scheme 1. Synthesis of Trichlorosilane-Containing TSMC

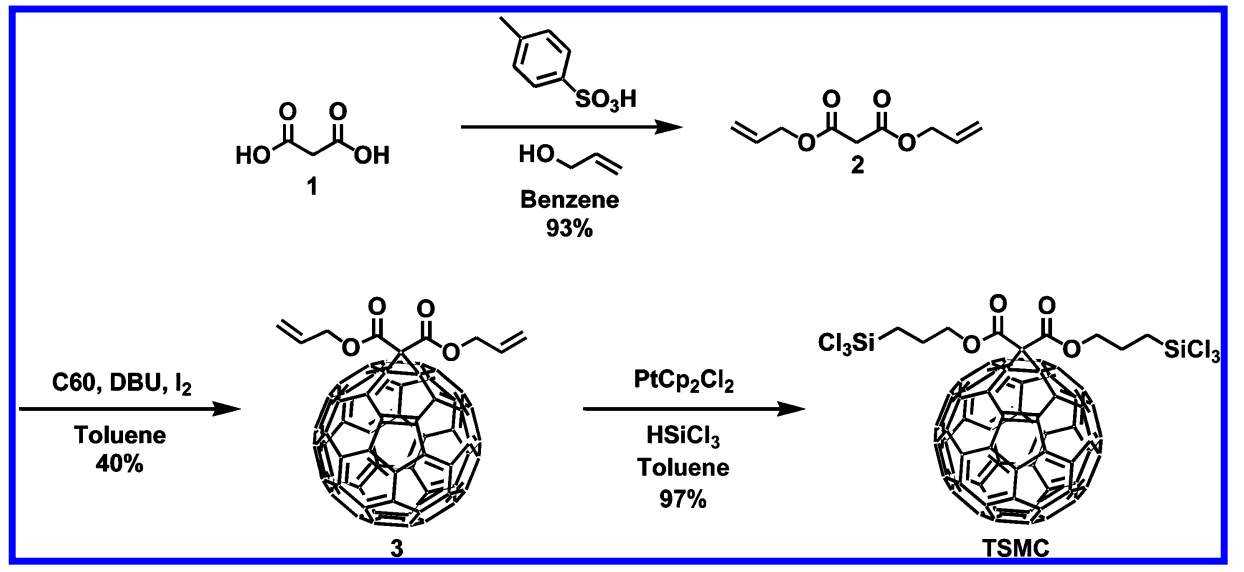

be eroded by the organic solvent used in the sequential active layer. ${ }^{27-29}$ To successfully incorporate an effective $C_{60}$ modifier into a multilayer inverted device, several interfacial aspects need to be taken into account: (1) solvent resistance against organic solvents, (2) passivation of hydroxyl groups on metal oxides, (3) coverage on metal oxides, and (4) surface nanoengineering of fullerene interlayer.

$\mathrm{C}_{60}$ derivatives functionalized with an anchoring group, such as carboxylic acid or phosphonic acid, have been developed to enhance the device characteristics. ${ }^{30-36}$ Through the chemical reactions between the anchoring groups and the hydroxyl groups on the metal oxide surface, an immobilized selfassembled monolayer (SAM) can be formed to overcome the erosion problem and terminate the hydroxyl groups. However, incomplete coverage at molecular scale and desorption of molecules during wet processing resulting in localized defects are the major drawbacks for the SAM strategy. ${ }^{37}$

To overcome these deficiencies, a cross-linkable fullerene material, $[6,6]$-phenyl- $\mathrm{C}_{61}$-butyric styryl dendron ester (PCBSD), using styryl group as thermal cross-linkers has been described. ${ }^{38}$ The formation of a cross-linked PCBSD (CPCBSD) allows successful deposition of sequential active layer without causing interfacial erosion. The C-PCBSD interlayer containing multiple layers of PCBSD molecules guarantees that the upper active layer and the bottom $\mathrm{ZnO}$ layer can be fully separated to avoid mutual diffusion. ${ }^{39}$ Therefore, the high efficiencies of the C-PCBSD-incorporated inverted solar cells have been accomplished. By using an anodic aluminum oxide (AAO)-template strategy to further engineer the nanostructure of C-PCBSD, an array of vertically aligned nanorods was achieved to create an ordered heterojunction. Such a nanostructured interlayer in the device enhanced charge generation and provided straight electron transport channels, leading to a high PCE of $7.3 \%$. $^{40}$

By integrating the concept of self-assembly and cross-linking in one system, we further developed a $\mathrm{PC}_{61} \mathrm{BM}$-based material, $[6,6]$-phenyl- $\mathrm{C}_{61}$-butyric oxetane dendron ester (PCBOD), functionalized with two oxetane groups that are capable of covalently anchoring at the surface of $\mathrm{TiO}_{x}$ and carrying out the intermolecular cross-linking. ${ }^{41}$ Nevertheless, to trigger cationic ring-opening reaction of the oxetane groups, addition of catalytic amount of a photoacid generator (PAG) in conjunction with UV-light illumination to in situ produce proton is essential. ${ }^{42-49}$ PAGs with the ionic nature may negatively act as a trap of electron transport. ${ }^{48-50}$ Moreover, to carry out the oxetane polymerization, isothermal heating at 150 ${ }^{\circ} \mathrm{C}$ for 30 min remains inevitable to promote the molecular movement required for the solid-state reaction. To simplify the process, it is thus desirable to utilize a fast and efficient reaction for the formation of $\mathrm{C}_{60}$ interlayer thereby reducing the fabrication time and cost.

Trichlorosilane moieties are known to readily undergo facile hydrolysis to produce polysiloxane in ambient air. Because of its high reactivity and wide availability, it is frequently used to 


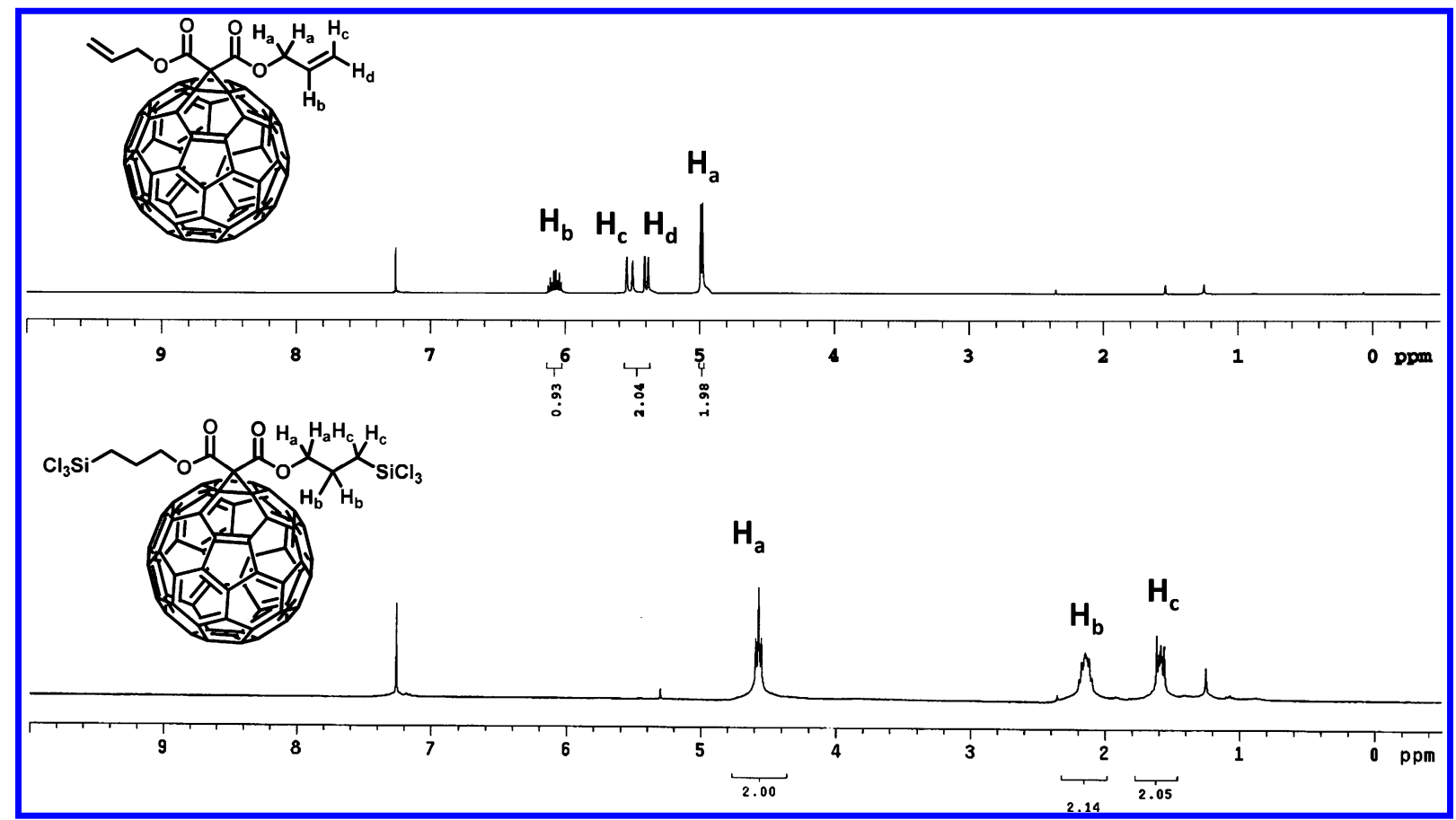

Figure 2. ${ }^{1} \mathrm{H}$ NMR spectra of compound 3 and TSMC.

implement self-assembly and/or cross-linking for the purpose of surface modification. ${ }^{51-57}$ However, to our surprise, introduction of trichlorosilane functionalities into fullerene derivatives for PSC applications has never been described. In this study, for the first time, we have successfully developed a new fullerene material, bis(2-(trichlorosilyl)propyl)malonate $\mathrm{C}_{60}$ (TSMC), containing two trichlorosilane groups (Figure 1). Without external thermal heating or UV irradiation, selfassembled and cross-linked TSMC (SA-C-TSMC) can be spontaneously generated on the $\mathrm{TiO}_{x}$ surface upon spincasting. The interlayer featuring vertically aligned nanoaggregates not only increased the charge-generating area but also provided the directional channels for the electron transportation. This strategy to accelerate the formation of solvent-resistant $\mathrm{C}_{60}$ modifier has led to improved performance of multilayer inverted solar cells.

\section{RESULTS AND DISCUSSION}

Synthesis. The synthesis of the TSMC is shown in Scheme 1. Esterification of malonic acid $\mathbf{1}$ with allyl alcohol in the presence of $p$-toluenesulfonic acid afforded compound 2 . Under basic condition, the Bingel reaction of compound 2 with $\mathrm{C}_{60}$ was carried out to furnish compound 3. Hydrosilylation of the olefins in 3 with trichlorosilane catalyzed by $\mathrm{Cp}_{2} \mathrm{PtCl}_{2}$ successfully furnished TSMC in $97 \%$ yield. The almost quantitative yield allows for the immeditate use of TSMC without further purification. The addition of trichlorosilyl groups selectively occurs at the terminal carbon of the olefins. It should be noted that the double bonds in the $\mathrm{C}_{60}$ core remain intact under the hydrosilylation condition. The ${ }^{1} \mathrm{H}$ NMR spectra of compound 3 and TSMC are compared and shown in Figure 2. After hydrosilylation, the two terminal olefinic protons on the compound 3 disappeared while the three new sets of the methylene protons in TSMC were observed, unambiguously indicative of the formation of trichlorosilane moieties.

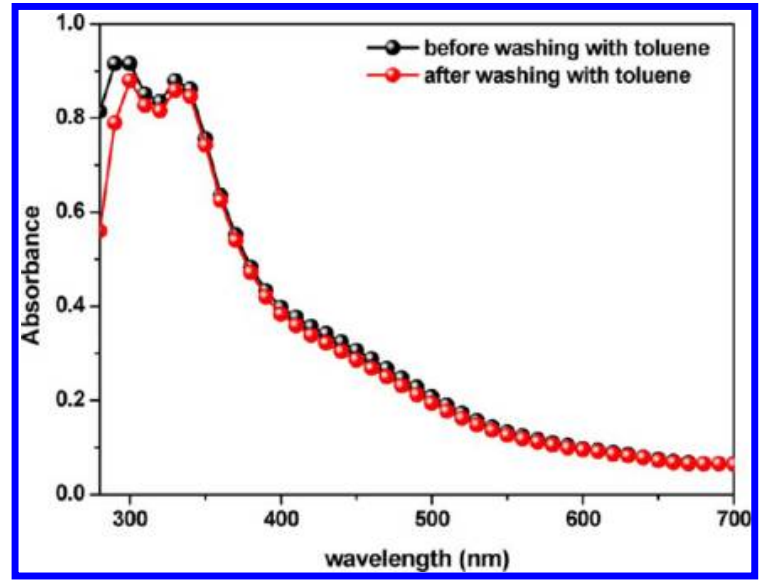

Figure 3. UV-Vis spectra of TSMC films before and after washing with toluene.

Contact Angle Measurements and Absorption Spectra. $\mathrm{TiO}_{x}$ was used to function as the hole-blocking and electron-selective layer in the inverted solar cells due to its high electron mobility and suitable energy levels (LUMO $=-4.4 \mathrm{eV}$, and $\mathrm{HOMO}=-7.6 \mathrm{eV})$. The $\mathrm{TiO}_{x}$ nanoparticles were prepared on the indium tin oxide ${ }^{26}$ substrate according to the reported procedures. ${ }^{35}$ An anhydrous toluene solution of TSMC was spin-cast on top of the surface of $\mathrm{ITO} / \mathrm{TiO}_{x}$. Contact angle measurement was used to monitor the surface alteration (Figure S1, Supporting Information). The bare surface of $\mathrm{ITO} / \mathrm{TiO}_{x}$ exhibited a contact angle of ca. $33^{\circ}$. After forming a self-assembled/cross-linked network of TSMC (SAC-TSMC) on the $\mathrm{TiO}_{x}$, the wetting contact angle to deionic water increased to $74^{\circ}$ as a result of the increasing hydrophobicity. Most importantly, this cross-linked network produced an adhesive and robust thin film with solvent resistance. After washing the modified surface with toluene, the contact angle remained almost unchanged $\left(72^{\circ}\right)$. We also 

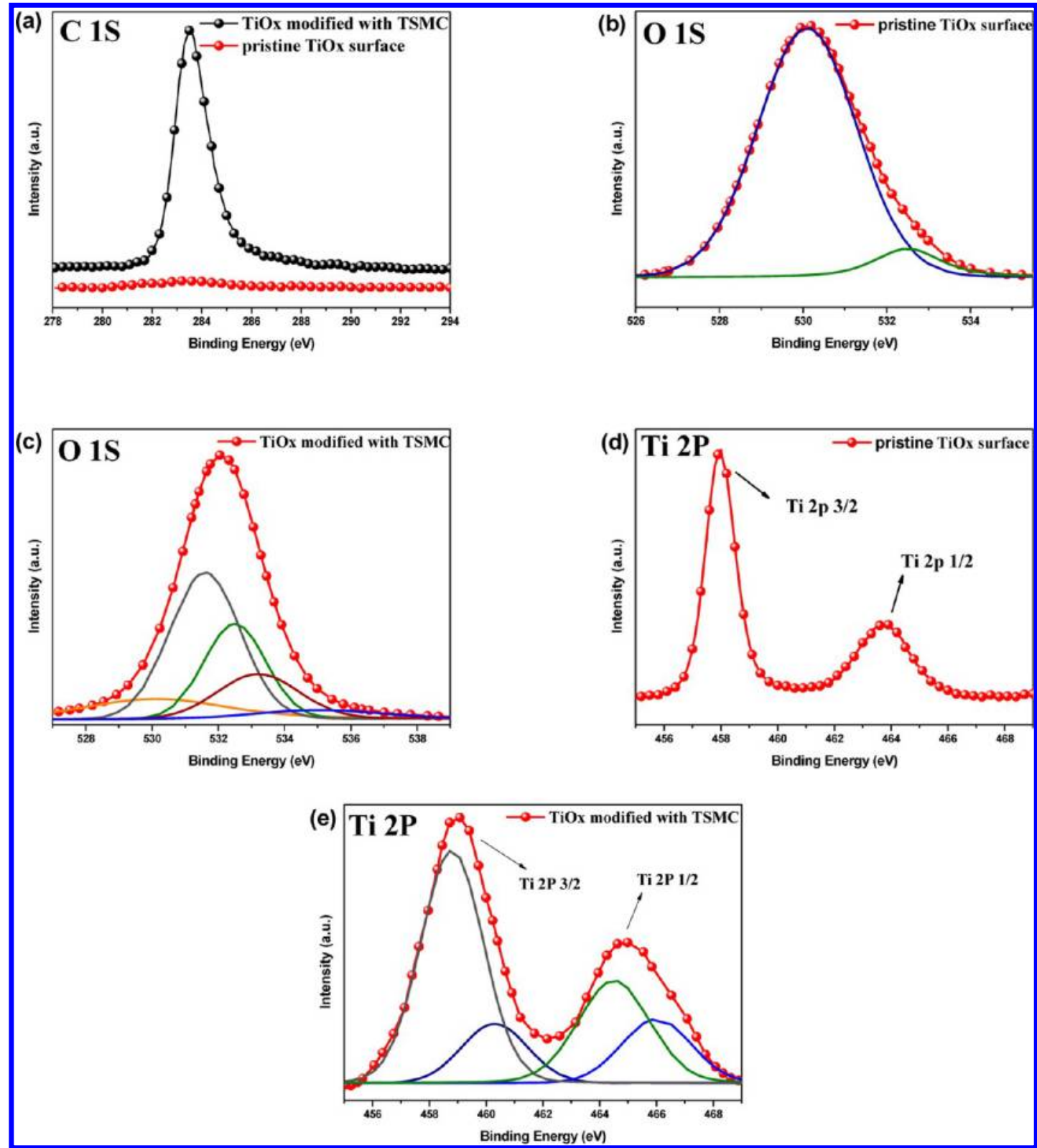

Figure 4. High resolution-XPS analysis of (a) carbon $1 \mathrm{~S}$ for ITO/ $\mathrm{TiO}_{x}$ and $\mathrm{ITO} / \mathrm{TiO}_{x} / \mathrm{SA}$-C-TSMC surfaces, $(\mathrm{b})$ oxygen $1 \mathrm{~S}$ for ITO/TiO surface, $_{x}$ (c) oxygen $1 \mathrm{~S}$ for $\mathrm{ITO} / \mathrm{TiO}_{x} / \mathrm{SA}$-C-TSMC surface, (d) titanium $2 \mathrm{P}$ for $\mathrm{ITO}_{\mathrm{TiO}}$ surface, and (e) titanium $2 \mathrm{P}$ for ITO/TiO $/$ /SA-C-TSMC surface.

carried out a comparison experiment. Compound 3, the precursor of TSMC without trichlorosilane groups, was also spin-cast on top of the $\mathrm{TiO}_{x}$, showing an enhanced contact angle of $70^{\circ}$ at the beginning. However, after washing with toluene, the contact angle dramatically decreased to $28^{\circ}$. The result indicates that compound 3 is unable to form a solventproof interlayer and reflects the importance of trichlorosliane functionality.

From the absorption spectra shown in Figure 3, the deposited SA-C-TSMC thin film exhibited a typical $\mathrm{C}_{60}$ absorption profile. The solvent resistance of the resulting SAC-TSMC thin film was also evidenced by the almost unchanged absorption spectra before and after rinsing with toluene.

XPS Measurements. For a detailed analysis of the chemical modification, the surfaces were characterized by X-ray photoelectron spectroscopy (XPS) as shown in Figure 4. Software Xpspeak41 was used for XPS deconvolution for the C 1S, O 1S and Ti $2 \mathrm{P}$ raw data. Strong carbon $1 \mathrm{~S}$ signal at $283.5 \mathrm{eV}$ was observed from the surface of $\mathrm{ITO} / \mathrm{TiO}_{x} / \mathrm{SA}-\mathrm{C}-\mathrm{TSMC}$, indicating the existence of the fullerene-containing TSMC. However, this carbon peak is not observable for the pristine ITO/TiO ${ }_{x}$ surface (Figure 4a).

For oxygen element analysis, subsequent to the peak deconvolution, the unmodified $\mathrm{TiO}_{x}$ surface exhibited a large fractional peaks at $530.1 \mathrm{eV}$ and a smaller signal at $532.5 \mathrm{eV}$, which correspond to $\mathrm{Ti}-\mathrm{O}-\mathrm{Ti}$ and $\mathrm{Ti}-\mathrm{OH}$ bonds, respectively, while three more peaks at $531.6 \mathrm{eV}(\mathrm{Ti}-\mathrm{O}-\mathrm{Si}$ signal) and 533.2 ( $\mathrm{Si}-\mathrm{O}-\mathrm{Si}$ signal) and $535.0 \mathrm{eV}(\mathrm{Si}-\mathrm{OH}$ signal) were observed from the surface of $\mathrm{ITO} / \mathrm{TiO}_{x} / \mathrm{SA}-\mathrm{C}$ TSMC. ${ }^{58,59}$ The Ti-O-Si bonding comes from the chemical modification between TSMC and $\mathrm{TiO}_{x}$ surface, and the $\mathrm{Si}-\mathrm{O}-$ $\mathrm{Si}$ bonding is a result of intermolecular cross-linking between the TSMC molecules. Besides, the $\mathrm{Si}-\mathrm{OH}$ bonding is originated from the hydrolysis of the trichlorosilane groups by moisture. The decrease of the signal intensity at $530.1 \mathrm{eV}$ and the emergence of the dominating peak at $531.6 \mathrm{eV}$ provide 


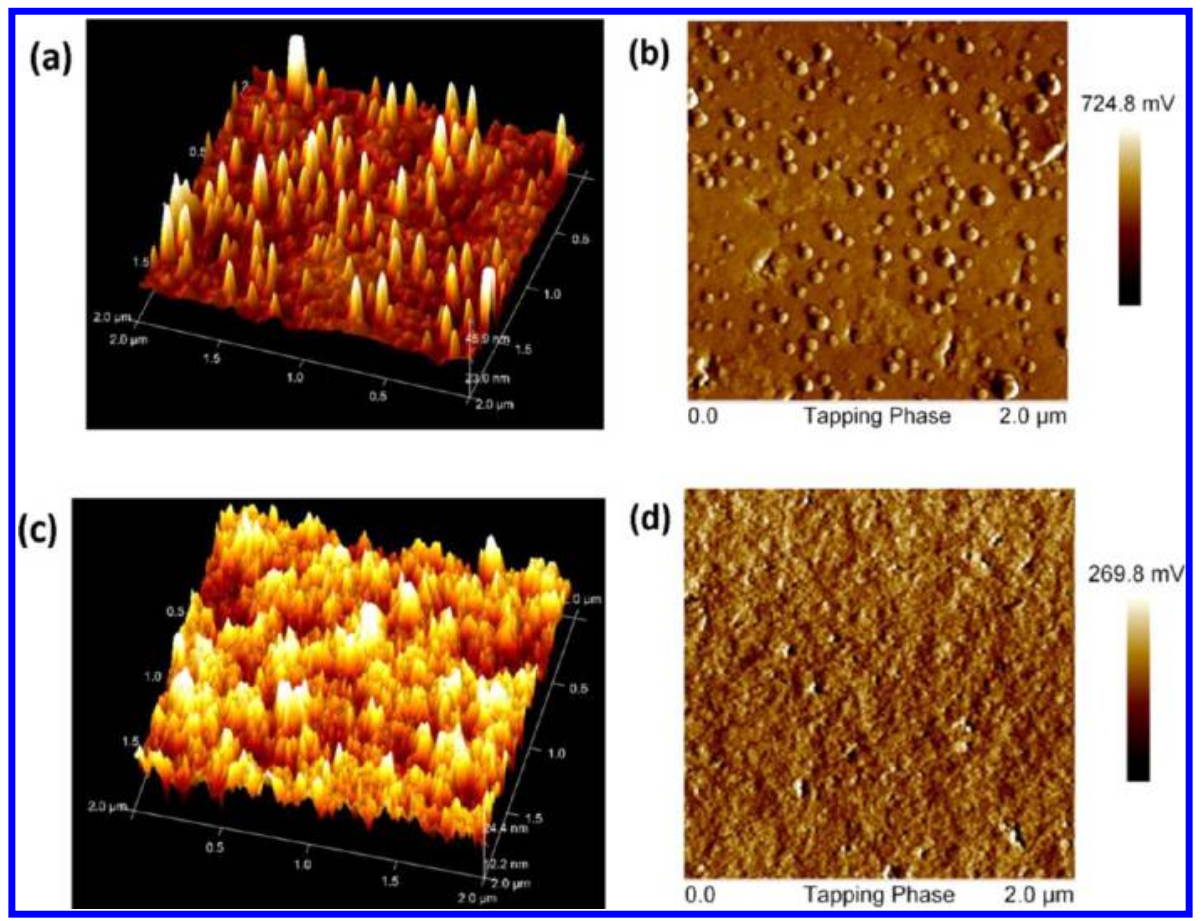

Figure 5. Atomic force microscopy images, (a) SA-C-TSMC 3D height image, (b) SA-C-TSMC phase image, (c) pristine TiO T $_{x}$ D height image, and (d) pristine $\mathrm{TiO}_{x}$ phase image.

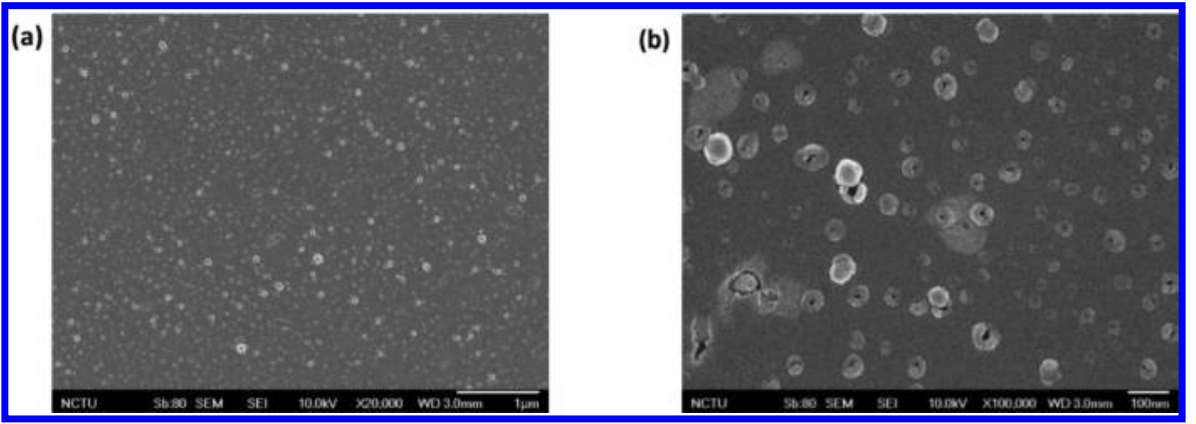

Figure 6. Scanning electron microscope images for the SA-C-TSMC surface at an original magnification of $20000 \times(a)$ and $100000 \times(b)$.

the direct evidence for the formation of SA-C-TSMC interlayer. Figure 4 shows the titanium $2 \mathrm{P}$ core-level spectra. The pristine $\mathrm{TiO}_{x}$ surface exhibited a $\mathrm{Ti} 2 \mathrm{P}_{3 / 2}$ peak and a $\mathrm{Ti} 2 \mathrm{P}_{1 / 2}$ peak centered at 458.8 and $464.5 \mathrm{eV}$, respectively, which are ascribed to the $\mathrm{Ti}^{4+}$ bonding to oxygen from the anatase titanium oxide, whereas the $\mathrm{TiO}_{x}$ modified with a SA-C-TSMC interlayer showed two peaks at 460.3 and $466.0 \mathrm{eV}$, respectively, which are assigned to the Ti $2 \mathrm{P}_{3 / 2}$ and $2 P_{1 / 2}$ signals of the $\mathrm{Ti}-\mathrm{O}-\mathrm{Si}$ moieties. These XPS analyses unambiguously confirm the coverage of SA-C-TSMC on the $\mathrm{TiO}_{x}$ surface.

Electrochemical Properties. The cyclic voltammogram of the cross-linked TSMC is shown in Figure S2, Supporting Information, and redox potential values are summarized in Table S1, Supporting Information. The cross-linked $\mathrm{C}_{60^{-}}$ monoadduct TSMC exhibited a similar LUMO energy level with $\mathrm{PC}_{61} \mathrm{BM}(-3.9 \mathrm{eV})$, showing its potential to serve as an good electron transport and hole-blocking layer .

Nanostructured Morphology. Atomic force microscopy (AFM) and scanning electron microscope (SEM) were employed to investigate the surface morphology. Interestingly, as shown in the AFM images (Figure 5), the pronounced nanostructures were found on the surface of the SA-C-TSMC layer with a RMS roughness of $5.26 \mathrm{~nm}$. These vertically grown semispherical nanoaggregates comprising the cross-linked TSMC aggregates are ca. $10-30 \mathrm{~nm}$ in height and ca. 20-60 $\mathrm{nm}$ in diameter. In contrast, the surface of the pristine $\mathrm{TiO}_{x}$ exhibited much smooth morphology with a RMS roughness ca. $3.49 \mathrm{~nm}$. Consistent with the AFM images, similar nanostructures on the SA-C-TSMC surface were also observable in the magnified SEM images (Figure 6).

The mechanism of the formation of TSMC layer on the $\mathrm{TiO}_{x}$ surface is proposed in Figure 7. Upon spin-coating, the nucleophilic hydroxyl groups on the surface can attack the electrophilic silicon atoms of trichlorosilanes to spontaneously form the self-assembled modification via the $\mathrm{Ti}-\mathrm{O}-\mathrm{Si}$ linkages (Figure 7a). In the mean time, intermolecular cross-linking between the TSMC molecules to form the multilayer network through the siloxane $\mathrm{Si}-\mathrm{O}-\mathrm{Si}$ linkages also proceeds efficiently (Figure $7 \mathrm{~b}$ ). Considering that hydrolysis of trichlorosilane groups with moisture is a fast and energetically favorable process, it is reasonable to expect that some of the TSMC molecules have started cross-linking and aggregating into nanoparticles suspended in the solution before spin-casting. The precross-linked nanoparticles deposited on the surface 


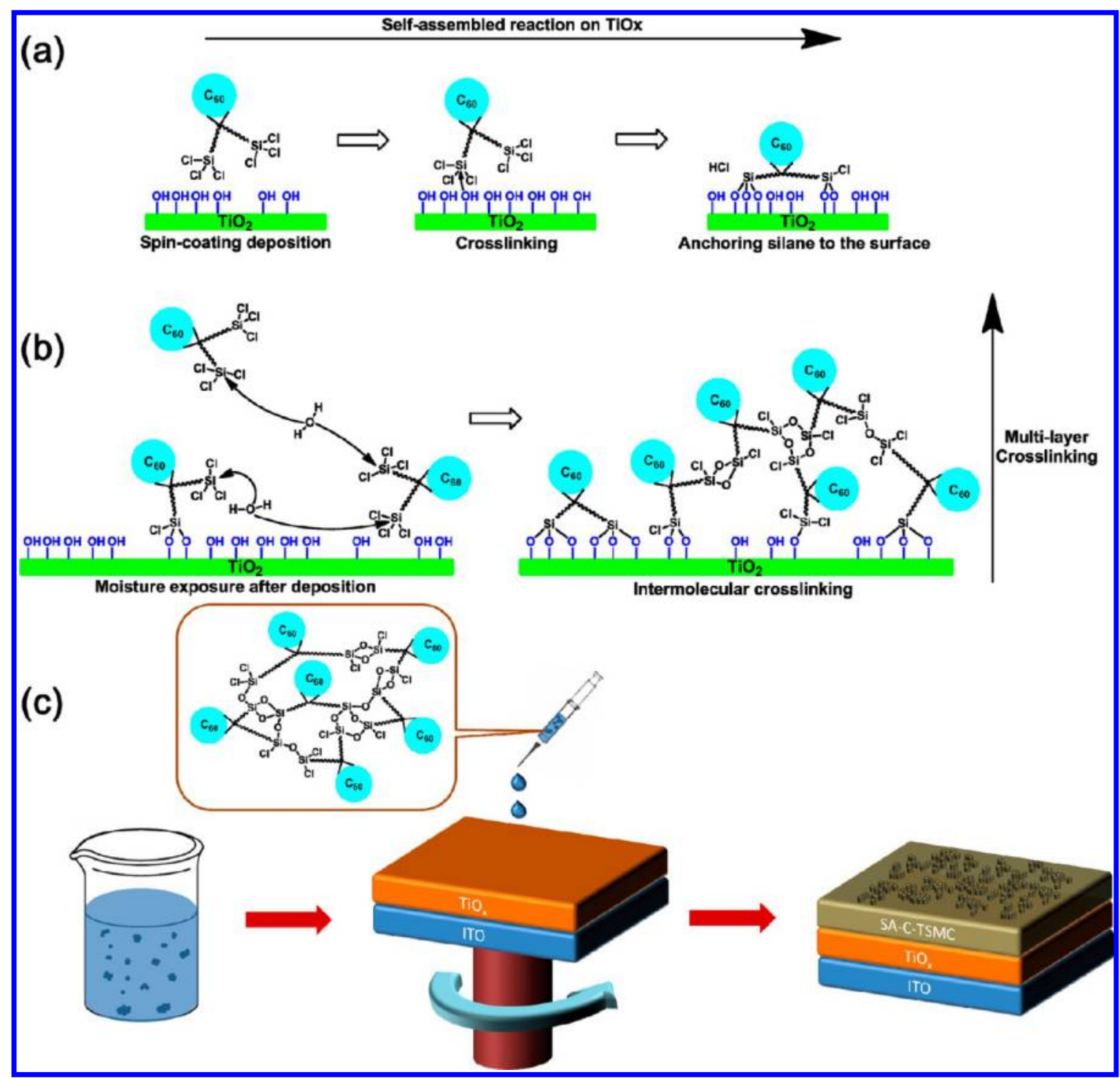

Figure 7. Hydrolysis of the trichlorosilane groups of TSMC: (a) self-assembled reaction on TiOx, (b) intermolecular cross-linking to form multilayer network, and (c) the formation of nanostructured SA-C-TSMC on the $\mathrm{TiO}_{x}$ surface.

were integrated into the SA-C-TSMC layer, thereby forming the vertically aligned nanostructures on the surface. This processing is illustrated in Figure $7 \mathrm{c}$.

Photovoltaic Performance. With this facile interfacial modification, we first fabricated a multilayer inverted device $\mathbf{B}$ with a configuration of ITO/ $\mathrm{TiO}_{x} / \mathrm{SA}-\mathrm{C}-\mathrm{TSMC} /$ P3HT:PC ${ }_{61} \mathrm{BM}$ (1:1,w/w)/PEDOT:PSS/Ag. Under otherwise identical conditions, a reference device A (ITO/ $/ \mathrm{TiO}_{x} /$ P3HT:PC ${ }_{61} \mathrm{BM} / \mathrm{PEDOT}: \mathrm{PSS} / \mathrm{Ag}$ ) without the SA-C-TSMC modifier was prepared for comparison. The $J-V$ curves of the devices are shown in Figure 8 and the device parameters are summarized in Table 1. Under AM 1.5G illumination at 100 $\mathrm{mW} / \mathrm{cm}^{2}$, device A showed a $V_{\mathrm{oc}}=0.58 \mathrm{~V}$, a $J_{\mathrm{sc}}=9.87 \mathrm{~mA} / \mathrm{cm}^{2}$, a $\mathrm{FF}=55.0 \%$ leading to a $\mathrm{PCE}=3.2 \%$. Encouragingly, device $\mathbf{B}$ exhibited enhancements of all the parameters, showing a $V_{\mathrm{oc}}=$ $0.60 \mathrm{~V}$, a $J_{\mathrm{sc}}=10.42 \mathrm{~mA} / \mathrm{cm}^{2}$, a FF $=61.70 \%$ and a higher PCE $=3.9 \%$. This efficiency represents a $22 \%$ improvement over the unmodified device A. After successfully demonstrating that SAC-TSMC interlayer can effectively improve the performance of the P3HT:PC ${ }_{61} \mathrm{BM}$-based inverted solar cell, we envisage that this strategy can be generally applied to the devices incorporating various photoactive materials. A p-type poly(diindenothiophene-alt-dithienylbenzothiadizole) copolymer (PDITTDTBT) was chosen to test the applicability of SA-CTSMC. $^{60}$ Control device $\mathrm{C}$ in the absence of the TSMC interlayer (ITO/ $\mathrm{TiO}_{x} /$ PDITTDTBT:PC ${ }_{71} \mathrm{BM}(1: 4, \mathrm{w} / \mathrm{w}) /$ $\left.\mathrm{MoO}_{x} / \mathrm{Ag}\right)$ and its corresponding device $\mathrm{D}\left(\mathrm{ITO} / \mathrm{TiO}_{x} / \mathrm{SA}\right.$ C-TSMC/PDITTDTBT:PC $\left.{ }_{71} \mathrm{BM}(1: 4, \mathrm{w} / \mathrm{w}) / \mathrm{MoO}_{x} / \mathrm{Ag}\right)$ were thus fabricated. In a similar manner, compared to device $\mathrm{C}$ without SA-C-TSMC $\left(V_{\text {oc }}=0.87 \mathrm{~V}, J_{s c}=9.94 \mathrm{~mA} / \mathrm{cm}^{2}, \mathrm{FF}=\right.$ $50.27 \%$ and PCE $=4.3 \%)$, device $\mathrm{D}$ exhibited $V_{\mathrm{oc}}=0.91 \mathrm{~V}, J_{\mathrm{sc}}=$ $11.54 \mathrm{~mA} / \mathrm{cm}^{2}, \mathrm{FF}=55.02 \%$, and $\mathrm{PCE}=5.8 \%$, which is a considerable enhancement of $35 \%$ in efficiency (Table 1 and Figure 8). The corresponding incident photon to charge carrier efficiency (IPCE) spectra of all the devices are shown in Figure $8 \mathrm{~b}$. This experiment demonstrates that the TSMC interlayer is effective not only for the $\mathrm{PC}_{61} \mathrm{BM}$-based system but also for the $\mathrm{PC}_{71} \mathrm{BM}$-based system.

Figure 9 illustrates the multiple effects of SA-C-TSMC interlayer on improving the electron transporting characteristics at the interfaces. For the contact with the upper active layer, compared to the inorganic-organic interface $\left(\mathrm{TiO}_{x} /\right.$ 


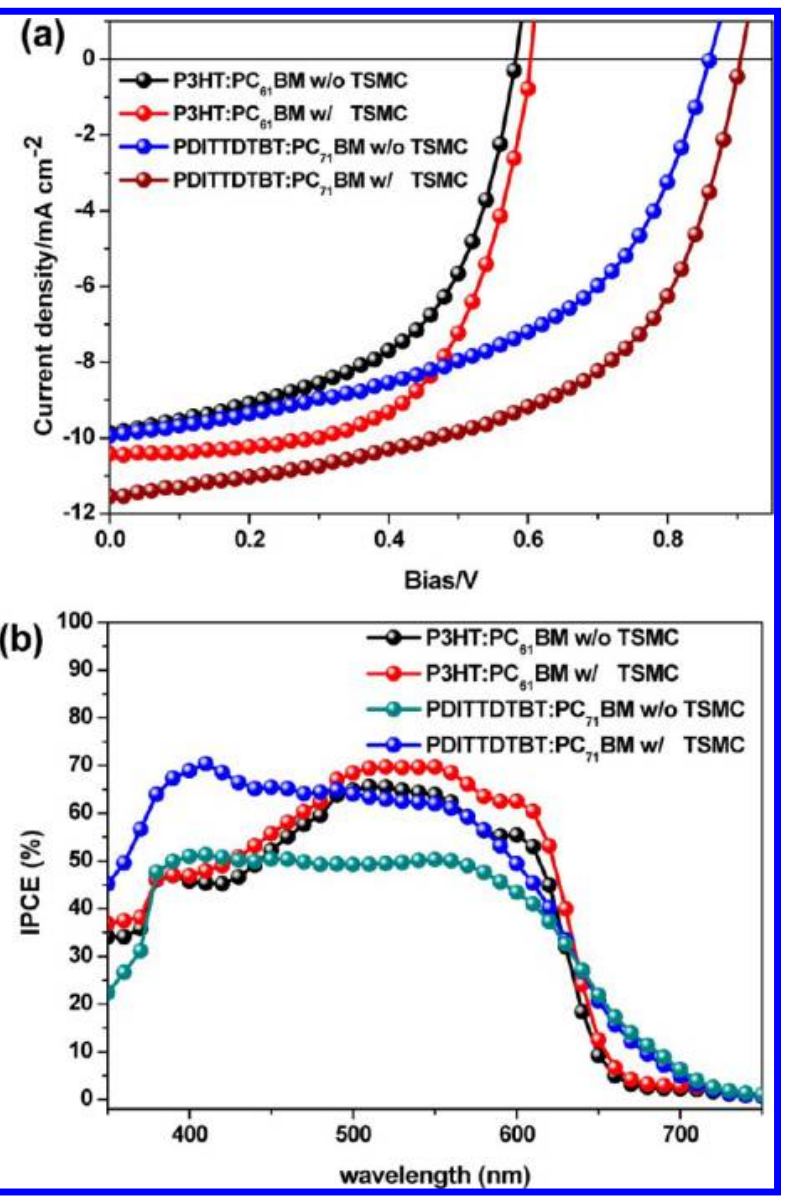

Figure 8. Current density-voltage characteristics (a) and the corresponding IPCE spectra (b) of devices A-D.

P3HT: $\mathrm{PC}_{61} \mathrm{BM}$ ) in device $\mathbf{A}$, the organic-organic (SA-CTSMC/P3HT: $\mathrm{PC}_{61} \mathrm{BM}$ ) interface with more compatible chemical interaction in device $\mathbf{B}$ enhances the electrical coupling and lowers the contact resistance, which facilitates the electron transport and reduces the charge recombination losses at this interface. Therefore, the series resistances of the SA-C-TSMC-modified devices decreased while the shunt resistances increased. Additionally, the fullerene-based SA-CTSMC interlayer provides an extra P3HT/SA-C-TSMC interface area for exciton dissociation (step 2 in Figure 9A), and serves as an energy gradient intermediate for the favorable electron transport. More importantly, the SA-C-TSMC interlayer featuring vertically aligned nanoaggregates turns out to be very beneficial due to the substantially enlarged chargegenerating interfacial area. Moreover, as soon as electrons are extracted by these nanoaggregates penetrating into the active layer, they can transport in the straight and directional

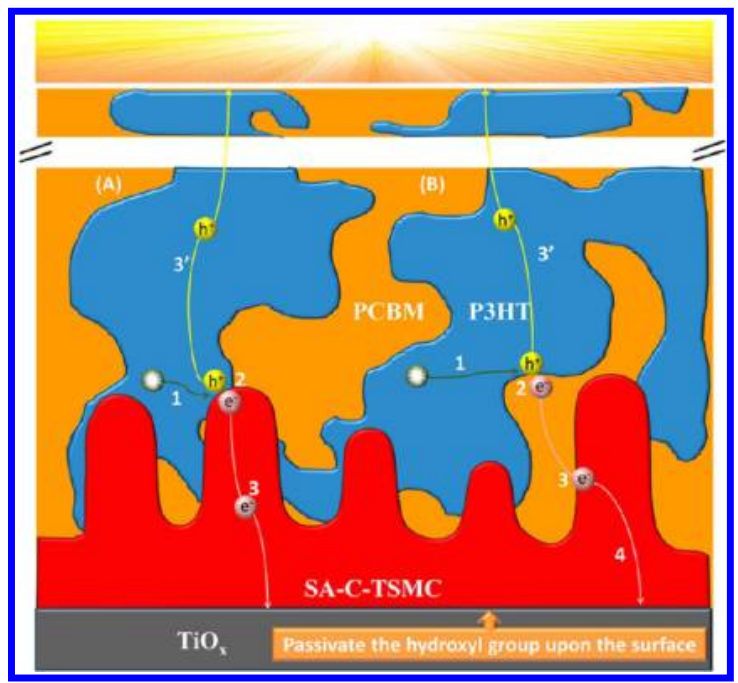

Figure 9. Illustration of the effects of the nanostructured SA-C-TSMC interlayer under illumination. Key: (A) (1) exciton diffuses to the junction of P3HT and SA-C-TSMC, (2) exciton dissociation at the interface, (3) directional electron transportation in the nanostructured SA-C-TSMC, $\left(3^{\prime}\right)$ hole transportation in the P3HT domains to the anode; (B) (1) exciton diffuses to the junction of P3HT and PCBM, (2) exciton dissociation at the interface, (3) facile electron transport from the PCBM domain to the SA-C-TSMC nanostructure, $\left(3^{\prime}\right)$ hole transportation in the $\mathrm{P} 3 \mathrm{HT}$ domains to the anode, (4) directional electron transportation in the nanostructured SA-C-TSMC.

pathways to avoid charge trapping and charge recombination (step 3 in Figure 9A and step 4 in Figure 9B).

Furthermore, due to the good compatibility between PCBM and SA-C-TSMC as well as the lower surface energy of P3HT, the active layer deposited on SA-C-TSMC tends to adopt a vertical phase separation where the bottom side is PCBM-rich and the upper side is P3HT-rich. This type of distribution of $n$ type and p-type materials in the active layer is ideal for inducing directional charge carrier transportation in inverted solar cells. Although the nanostructures on the TSMC surface are not as ordered as those fabricated by AAO-template strategy, ${ }^{61-63}$ this simple and rapid processing approach is much more practical for mass production. For the contact with the bottom $\mathrm{TiO}_{x}$ layer, the formation of SA-C-TSMC modifier in device B and device $\mathrm{D}$ not only terminates the hydroxyl groups on the $\mathrm{TiO}_{x}$ surface to passivate the surface traps, but also forms a more intimate contact to facilitate the electron transport.

The $J-V$ characteristics of devices A-D in the dark were also investigated (Figure S4, Supporting Information). Device B and $\mathrm{D}$, with the interlayer, showed a significant reduction in dark current under reverse bias, leading to a higher rectification ratio than the corresponding device $\mathrm{A}$ and $\mathrm{C}$. This result may suggest that the SA-C-TSMC interlayer in device B and D can indeed

Table 1. Performance Parameters for Devices A, B, C and D

$\begin{array}{ccccc}\text { device } & V_{\text {oc }}(\mathrm{V}) & J_{\mathrm{sc}}\left(\mathrm{mA} / \mathrm{cm}^{2}\right) & \text { FF }(\%) & \text { PCE (\%) } \\ \text { A } & 0.58 & 9.87 & 55.00 & 3.2(2.99 \pm 0.21)^{a} \\ \text { B } & 0.60 & 10.42 & 61.70 & 3.9(3.82 \pm 0.16)^{a} \\ \text { C } & 0.87 & 9.94 & 50.27 & 4.3(4.18 \pm 0.23)^{a} \\ \text { D } & 0.91 & 11.54 & 55.02 & 5.8(5.65 \pm 0.15)^{a}\end{array}$

${ }^{a}$ Average PCE values with standard deviation. Key: device A, ITO/TiO $/$ P3HT:PC ${ }_{61} \mathrm{BM}(1: 1, \mathrm{w} / \mathrm{w}) / \mathrm{PEDOT}: \mathrm{PSS} / \mathrm{Ag} ; \mathrm{device} \mathrm{B}, \mathrm{ITO} / \mathrm{TiO}_{x} /$

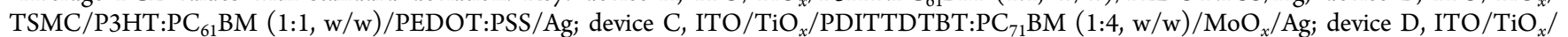
TSMC/PDITTDTBT:PC 71 BM (1:4, w/w)/ $\mathrm{MoO}_{x} / \mathrm{Ag}$. 
passivate the local shunts at the $\mathrm{TiO}_{x}$ interface and therefore block the injection of holes in the leakage pathways of the $\mathrm{TiO}_{x}$. This is also supported by the much increased shunt (parallel) resistance $\left(R_{\mathrm{sh}}\right)$ of devices $\mathrm{B}\left(70.4 \mathrm{~K} \Omega \mathrm{cm}^{2}\right)$ and $\mathrm{D}(192.3 \mathrm{~K} \Omega$ $\left.\mathrm{cm}^{2}\right)$ compared to their reference devices $\mathrm{A}\left(27.3 \mathrm{~K} \Omega \mathrm{cm}^{2}\right)$ and C $\left(9.3 \mathrm{~K} \Omega \mathrm{cm}^{2}\right)$, respectively (Table 1$)$. Consequently, the reduced leakage current leads to improved $V_{\text {oc }}$ and FF.

\section{CONCLUSIONS}

An n-type $\mathrm{C}_{60}$ interlayer incorporated in a multilayer inverted device has been demonstrated to improve the device performance by modulating the electronic properties at the interfaces. Development of a $\mathrm{C}_{60}$ derivative utilizing a rapid cross-linking reaction plays a key role in simplifying device fabrication and improving device characteristics. For the first time, we has synthesized a novel cross-linkable bis(2-(trichlorosilyl)propyl)malonate $\mathrm{C}_{60}$ consisting of two trichlorosilane groups in high yield. Without thermal heating and UV irradiation, hydrolysis of the trichlorosilyl groups in TSMC via self-assembly/crosslinking generates a SA-C-TSMC layer that simultaneously achieves (1) solvent resistance against organic solvents, (2) passivation of hydroxyl groups on $\mathrm{TiO}_{x},(3)$ coverage over $\mathrm{TiO}_{x}$, and (4) formation of nanostructured surface. The nanoaggregates on the SA-C-TSMC layer provide extra charge-generating interfacial area and straight electron transport pathways. The P3HT: $\mathrm{PC}_{61} \mathrm{BM}$-based device with this $\mathrm{C}_{60^{-}}$ modifier showed a $22 \%$ improvement of efficiency over the device without this layer. This strategy can be applied to the device incorporating a conjugated polymer, PDITTDTBT, yielding a high PCE of $5.8 \%$ which represents a $35 \%$ enhancement over its control device. We envision that this new cross-linkable material can be widely used to produce efficient and cost-effective inverted solar cells.

\section{EXPERIMENTAL SECTION}

General Measurement and Characterization. UV data were collected by the HITACHI U-4100 spectrophotometer and contact angle measurements were performed with Face Model CAM-Micro. The electrochemical cyclic voltammetry $(\mathrm{CV})$ was conducted on a $\mathrm{CH}$ Instruments Model 611D. A carbon glass coated with a thin fullerene film was used as the working electrode and $\mathrm{Ag} / \mathrm{Ag}^{+}$electrode as the reference electrode, while $0.1 \mathrm{M}$ tetrabutylammonium hexafluorophosphate $\left(\mathrm{Bu}_{4} \mathrm{NPF}_{6}\right)$ in acetonitrile was the electrolyte. HR-XPS was carried out by PHI Quantera SXM form ULVAC-PHI. Surface topography was investigated by a JEOL JSM-7401F model scanning electron microscope (SEM) with an accelerating voltage of $10 \mathrm{kV}$ and Veeco Nanoscope 3100 AFM, respectively. The standard tips used in AFM are "type Tap 300; L, 135 m; FREQ $300 \mathrm{MHz}$;, $40 \mathrm{~N} / \mathrm{m}$."

Device Fabrication. ITO-coated glass substrates were ultrasonically cleaned sequentially in detergent, water, acetone and isopropyl alcohol. A 1 wt \% titanium isopropoxide (Aldrich, 99.999\%) solution in isopropyl alcohol was then spin-coated on the ITO substrate at $3000 \mathrm{rpm}$ for $30 \mathrm{~s}$, kept at room temperature for $12 \mathrm{~h}$, and then annealed at $250{ }^{\circ} \mathrm{C}$ for $30 \mathrm{~min}$ to furnish a $40 \mathrm{~nm}$ thick $\mathrm{TiO}_{x}$ electron extraction layer. For the devices with cross-linked TSMC interlayer, a solution of TSMC in anhydrous toluene $\left(3 \mathrm{mg} \mathrm{mL}^{-1}\right)$ was spin-cast on top of the $\mathrm{TiO}_{x}$ layer at $5000 \mathrm{rpm}$ for $2 \mathrm{~min}$, followed by exposure to air for $10 \mathrm{~min}$. The active layer was then prepared by spin-casting a solution of P3HT:PC ${ }_{61} \mathrm{BM}$ (1:1 by weight) in 1,2-dichlorobenzene $\left(36 \mathrm{mg} \mathrm{mL} \mathrm{m}^{-1}\right.$ ) at $500 \mathrm{rpm}$ for $60 \mathrm{~s}$ or a solution of PDITTDTBT:PC ${ }_{71} \mathrm{BM}$ (1:4 by weight) in 1,2-dichlorobenzene (35 $\mathrm{mg} \mathrm{mL} \mathrm{m}^{-1}$ ) at $900 \mathrm{rpm}$ for $180 \mathrm{~s}$. The P3HT:PC ${ }_{61} \mathrm{BM}$ film was allowed to slowly evaporate in a covered Petri dish and then thermally annealed at $150{ }^{\circ} \mathrm{C}$ for $10 \mathrm{~min}$. Afterward, an hole-extraction layer of either a $80 \mathrm{~nm}$ thick PEDOT:PSS or a $10 \mathrm{~nm}$ thick $\mathrm{MoO}_{x}$ was deposited on top of the active layer. Finally, a $150 \mathrm{~nm} \mathrm{Ag}$ anode was evaporated through a shadow mask under high vacuum $\left(<10^{-6}\right.$ Torr $)$. Each device is constituted of 4 pixels defined by an active area of 0.04 $\mathrm{cm}^{2}$. The current density-voltage $(J-V)$ characteristics were measured under simulated air mass 1.5 global (AM 1.5G) irradiation of $100 \mathrm{~mW}$ $\mathrm{cm}^{-2}$.

Synthesis of Diallyl Malonate (2). To a solution of malonic acid $(5 \mathrm{~g}, 48.08 \mathrm{mmol})$ and $p$-toluenesulfonic acid $(0.82 \mathrm{~g}, 4.81 \mathrm{mmol})$ in toluene $(250 \mathrm{~mL})$ was added prop-2-en-1-ol $(27 \mathrm{~g}, 384.6 \mathrm{mmol})$. The reaction mixture was then refluxed for $6 \mathrm{~h}$ with a dean-stark trap. After cooling to room temperature, it was extracted by ether and water, followed by sodium bicarbonate and brine. The combined organic layer was dried over $\mathrm{MgSO}_{4}$ and evaporated under reduced pressure. The residue was purified by column chromatography on silica gel (ethyl acetate/hexane, $1 / 4 \mathrm{v} / \mathrm{v}$ ) to give a yellow oil $2\left(8.26 \mathrm{~g} \mathrm{93 \% ).}{ }^{1} \mathrm{H}\right.$ NMR $\left(300 \mathrm{MHz}, \mathrm{CDCl}_{3}\right): \delta 3.43(\mathrm{~s}, 2 \mathrm{H}), 4.64(\mathrm{~d}, 4 \mathrm{H}), 5.28(\mathrm{q}, 4 \mathrm{H})$, 5.84-5.95 (m, 2H).

Synthesis of Diallyl Malonate Fullerene (3). To a solution of $\mathrm{C}_{60}(1 \mathrm{~g}, 1.39 \mathrm{mmol})$, iodine $(0.35 \mathrm{~g}, 1.38 \mathrm{mmol})$ and $1,8-$ diazabicyclo[5,4,0] undec-7-ene $(0.42 \mathrm{~g}, 2.78 \mathrm{mmol})$ in toluene $(700$ $\mathrm{mL}$ ) was slowly added a solution of diallyl malonate 2 (0.25 g, 1.39 $\mathrm{mmol})$ in toluene $(100 \mathrm{~mL})$. The reaction mixture was stirred at room temperature for $24 \mathrm{~h}$ and sodium thiosulfate aqueous solution was then added to quench the excessive iodine. The organic layer was collected and dried by $\mathrm{MgSO}_{4}$. After removal of the solvent under reduced pressure, the residue was purified by silica gel chromatography with toluene/hexane $(2 / 1, \mathrm{v} / \mathrm{v})$ as the eluent to give a crude product. It was reprecipitated from toluene/methanol to give a brown solid 3 $(0.48 \mathrm{~g}, 40 \%) .{ }^{1} \mathrm{H}$ NMR $\left(300 \mathrm{MHz}, \mathrm{CDCl}_{3}\right): \delta 4.98$ (d, 4H), $5.49(\mathrm{q}$, $4 \mathrm{H}), 6.03-6.13(\mathrm{~m}, 2 \mathrm{H}) .{ }^{13} \mathrm{C} \mathrm{NMR}\left(\mathrm{CDCl}_{3}, 75 \mathrm{MHz}\right): \delta 68.0,71.7$, $120.3,131.1,139.3,141.2,142.1142 .4,143.2,143.3,143.3,144.1$, 144.9, 144.9, 145.1, 145.3, 145.4, 145.4, 145.5, 163.5.

Synthsis of Bis(2-(trichlorosilyl)propyl) Malonate $\mathrm{C}_{60}$ (TSMC). Under nitrogen atmosphere, diallyl-malonate fullerene 3 (0.05 g, $0.0553 \mathrm{mmol}$ ), one spatula of dicyclopentadienyl platinum dichloride, trichlorosilane $(0.0176 \mathrm{~g}, 0.13 \mathrm{mmol})$ and anhydrous toluene $(5 \mathrm{~mL})$ were mixed together in a Schlenk tube. The reaction mixture was then stirred at $70{ }^{\circ} \mathrm{C}$ for $24 \mathrm{~h}$, cooled to room temperature, and then added dropwise into dry hexane $(50 \mathrm{~mL})$ to furnish a brown precipitate $4(63$ $\mathrm{mg}, 97 \%) .{ }^{1} \mathrm{H}$ NMR $\left(300 \mathrm{MHz}, \mathrm{CDCl}_{3}\right): \delta 1.56-1.62(\mathrm{~m}, 4 \mathrm{H}), 2.12-$ $2.17(\mathrm{~m}, 4 \mathrm{H}), 4.57(\mathrm{t}, 4 \mathrm{H}, J=6.3 \mathrm{~Hz}) .{ }^{13} \mathrm{C} \mathrm{NMR}\left(\mathrm{CDCl}_{3}, 75 \mathrm{MHz}\right): \delta$ $21.1,22.2,67.8,71.5,139.2,141.3,142.1,142.4,143.3,143.3,143.4$, $144.1,144.8,145.0,145.2,145.3,145.5,145.6,163.7$.

\section{ASSOCIATED CONTENT}

\section{S Supporting Information}

Contact angle measurement, cyclic voltammogram of the crosslinked TSMC, redox potential and molecular energy level of TSMC, dark current curves of the devices, and ${ }^{1} \mathrm{H}$ and ${ }^{13} \mathrm{C}$ NMR spectra of the new compounds. This material is available free of charge via the Internet at http://pubs.acs.org/.

\section{AUTHOR INFORMATION}

\section{Corresponding Author}

*E-mail: (Y.-J.C.) yjcheng@mail.nctu.edu.tw; (C.-L.W.) kclwang@nctu.edu.tw; (C.-S.H.) cshsu@mail.nctu.edu.tw.

\section{Notes}

The authors declare no competing financial interest.

\section{ACKNOWLEDGMENTS}

We thank the National Science Council and the "ATU Program" of the Ministry of Education, and Center for Interdisciplinary Science (CIS) of the National Chiao Tung University, Taiwan, for financial support.

\section{REFERENCES}

(1) Chen, J.; Cao, Y. Acc. Chem. Res. 2009, 42, 1709-1718.

(2) Li, Y. Acc. Chem. Res. 2012, 45, 723-733. 
(3) Li, Y.; Zou, Y. Adv. Mater. 2008, 20, 2952-2958.

(4) Thompson, B. C.; Frechet, J. M. Angew. Chem., Int. Ed. 2008, 47, $58-77$.

(5) Arias, A. C.; MacKenzie, J. D.; McCulloch, I.; Rivnay, J.; Salleo, A. Chem. Rev. 2010, 110, 3-24.

(6) Cheng, Y.-J.; Yang, S.-H.; Hsu, C.-S. Chem. Rev. 2009, 109, $5868-5923$

(7) Günes, S.; Neugebauer, H.; Sariciftci, N. S. Chem. Rev. 2007, 107, 1324-1338.

(8) Duan, C.; Huang, F.; Cao, Y. J. Mater. Chem. 2012, 22, 10416.

(9) He, F.; Yu, L. J. Phys. Chem. Lett. 2011, 2, 3102-3113.

(10) Zhou, H.; Yang, L.; You, W. Macromolecules 2012, 45, 607-632.

(11) Li, G.; Zhu, R.; Yang, Y. Nat. Photonics 2012, 6, 153-161.

(12) Huo, L.; Hou, J. Poly. Chem. 2011, 2, 2453.

(13) Yu, G.; Gao, J.; Hummelen, J. C.; Wudl, F.; Heeger, A. J. Science 1995, 270, 1789-1791.

(14) de Jong, M. P.; van Ijzendoorn, L. J.; de Voigt, M. J. A. Appl. Phys. Lett. 2000, 77, 2255.

(15) Gong, X.; Moses, D.; Heeger, A. J.; Liu, S.; Jen, A. K. Y. Appl. Phys. Lett. 2003, 83, 183.

(16) Wong, K. W.; Yip, H. L.; Luo, Y.; Wong, K. Y.; Lau, W. M.; Low, K. H.; Chow, H. F.; Gao, Z. Q.; Yeung, W. L.; Chang, C. C. Appl. Phys. Lett. 2002, 80, 2788.

(17) Nguyen, T. P.; de Vos, S. A. Appl. Surf. Sci. 2004, 221, 330-339.

(18) Mor, G. K.; Shankar, K.; Paulose, M.; Varghese, O. K.; Grimes,

C. A. Appl. Phys. Lett. 2007, 91, 152111.

(19) Steim, R.; Choulis, S. A.; Schilinsky, P.; Brabec, C. J. Appl. Phys. Lett. 2008, 92, 093303.

(20) Waldauf, C.; Morana, M.; Denk, P.; Schilinsky, P.; Coakley, K.; Choulis, S. A.; Brabec, C. J. Appl. Phys. Lett. 2006, 89, 233517.

(21) White, M. S.; Olson, D. C.; Shaheen, S. E.; Kopidakis, N.; Ginley, D. S. Appl. Phys. Lett. 2006, 89, 143517.

(22) Yang, T.; Cai, W.; Qin, D.; Wang, E.; Lan, L.; Gong, X.; Peng, J.; Cao, Y. J. Phys. Chem. C 2010, 114, 6849-6853.

(23) Einat, M.; Einat, N. Appl. Phys. Lett. 2006, 89, 073505.

(24) Lee, S.; Koo, B.; Shin, J.; Lee, E.; Park, H.; Kim, H. Appl. Phys. Lett. 2006, 88, 162109.

(25) Chua, L.-L.; Zaumseil, J.; Chang, J.-F.; Ou, E. C. W.; Ho, P. K. H.; Sirringhaus, H.; Friend, R. H. Nature 2005, 434, 194-199.

(26) Wei, Q.; Nishizawa, T.; Tajima, K.; Hashimoto, K. Adv. Mater. 2008, 20, 2211-2216.

(27) Liang, C. W.; Su, W. F.; Wang, L. Y. Appl. Phys. Lett. 2009, 95, 133303.

(28) Cheng, Y.-J.; Liao, M.-H.; Shih, H.-M.; Shih, P.-I.; Hsu, C.-S. Macromolecules 2011, 44, 5968-5976.

(29) Huang, J.-S.; Chou, C.-Y.; Lin, C.-F. Sol. Energy Mater. Sol. Cells 2010, 94, 182-186.

(30) Ma, H.; Yip, H.-L.; Huang, F.; Jen, A. K. Y. Adv. Funct. Mater. 2010, 20, 1371-1388.

(31) Hau, S. K.; Yip, H.-L.; Baek, N. S.; Zou, J.; O’Malley, K.; Jen, A.

K. Y. Appl. Phys. Lett. 2008, 92, 253301.

(32) Hau, S. K.; Yip, H.-L.; Ma, H.; Jen, A. K. Y. Appl. Phys. Lett. 2008, 93, 233304.

(33) Duan, C.-H.; Zhong, C.-M.; Liu, C.-C.; Huang, F.; Cao, Y. Chem. Mater. 2012, 24, 1682-1689.

(34) Yip, H.-L.; Jen, A. K. Y. Energy Environ. Sci. 2012, 5, 5994.

(35) Hau, S. K.; Yip, H.-L.; Acton, O.; Baek, N. S.; Ma, H.; Jen, A. K. Y. J. Mater. Chem. 2008, 18, 5113.

(36) Li, C.-Z.; Yip, H.-L.; Jen, A. K. Y. J. Mater. Chem. 2012, 22, 4161.

(37) Goh, C.; Scully, S. R.; McGehee, M. D. J. Appl. Phys. 2007, 101, 114503.

(38) Hsieh, C.-H.; Cheng, Y.-J.; Li, P.-J.; Chen, C.-H.; Dubosc, M.; Liang, R.-M.; Hsu, C.-S. J. Am. Chem. Soc. 2010, 132, 4887-4893.

(39) Cheng, Y.-J.; Hsieh, C.-H.; He, Y.; Hsu, C.-S.; Li, Y. J. Am. Chem. Soc. 2010, 132, 17381-17383.

(40) Chang, C.-Y.; Wu, C.-E.; Chen, S.-Y.; Cui, C.; Cheng, Y.-J.; Hsu, C.-S.; Wang, Y.-L.; Li, Y. Angew. Chem., Int. Ed. 2011, 50, 9386-9390.

(41) Cheng, Y.-J.; Cao, F.-Y.; Lin, W.-C.; Chen, C.-H.; Hsieh, C.-H. Chem. Mater. 2011, 23, 1512-1518.
(42) Gather, M. C.; Köhnen, A.; Falcou, A.; Becker, H.; Meerholz, K. Adv. Funct. Mater. 2007, 17, 191-200.

(43) Köhnen, A.; Riegel, N.; Kremer, J. H. W. M.; Lademann, H.; Müller, D. C.; Meerholz, K. Adv. Mater. 2009, 21, 879-884.

(44) Zacharias, P.; Gather, M. C.; Rojahn, M.; Nuyken, O.; Meerholz, K. Angew. Chem., Int. Ed. 2007, 46, 4388-4392.

(45) Huang, F.; Cheng, Y.-J.; Zhang, Y.; Liu, M. S.; Jen, A. K. Y. J. Mater. Chem. 2008, 18, 4495.

(46) Bacher, E.; Bayerl, M.; Rudati, P.; Reckefuss, N.; Müller, C. D.; Meerholz, K.; Nuyken, O. Macromolecules 2005, 38, 1640-1647.

(47) Niikura, H.; Legare, F.; Hasbani, R.; Ivanov, M. Y.; Villeneuve, D. M.; Corkum, P. B. Nature 2003, 421, 826-829.

(48) Chiesa, M.; Paganini, M. C.; Giamello, E.; Di Valentin, C.; Pacchioni, G. Angew. Chem., Int. Ed. 2003, 42, 1759-1761.

(49) Drees, M.; Hoppe, H.; Winder, C.; Neugebauer, H.; Sariciftci, N. S.; Schwinger, W.; Schäffler, F.; Topf, C.; Scharber, M. C.; Zhu, Z.; Gaudiana, R. J. Mater. Chem. 2005, 15, 5158.

(50) Ichimura, A. S.; Dye, J. L.; Camblor, M. A.; Villaescusa, L. A. J. Am. Chem. Soc. 2002, 124, 1170-1171.

(51) Yan, H.; Scott, B. J.; Huang, Q.; Marks, T. J. Adv. Mater. 2004, 16, 1948-1953.

(52) Shtein, M.; Mapel, J.; Benziger, J. B.; Forrest, S. R. Appl. Phys. Lett. 2002, 81, 268

(53) Ortiz, R. O. P.; Facchetti, A.; Marks, T. J. Chem. Rev. 2009, 110, 205-239.

(54) Huang, Q.; Evmenenko, G. A.; Dutta, P.; Lee, P.; Armstrong, N. R; Marks, T. J. J. Am. Chem. Soc. 2005, 127, 10227-10242.

(55) Kim, C.; Wang, Z.; Choi, H.-J.; Ha, Y.-G.; Facchetti, A.; Marks, T. J. J. Am. Chem. Soc. 2008, 130, 6867-6878.

(56) Weitz, R. T.; Zschieschang, U.; Effenberger, F.; Klauk, H.; Burghard, M.; Kern, K. Nano Lett. 2006, 7, 22-27.

(57) Novikov, V. N.; Sokolov, A. P. Nature 2004, 431, 961-963.

(58) Aronson, B. J.; Blanford, C. F.; Stein, A. Chem. Mater. 1997, 9, 2842-2851.

(59) Metson, J. B.; Hyland, M. M.; Gillespie, A.; HemmingsenJensen, M. Colloids Surf., A 1994, 93, 173-180.

(60) Cheng, Y.-J.; Cheng, S.-W.; Chang, C.-Y.; Kao, W.-S.; Liao, M.H.; Hsu, C.-S. Chem. Commun. 2012, 48, 3203-3205.

(61) Liu, N. W.; Liu, C. Y.; Wang, H. H.; Hsu, C. F.; Lai, M. Y.; Chuang, T. H.; Wang, Y. L. Adv. Mater. 2008, 20, 2547-2551.

(62) Wang, H. H.; Liu, C. Y.; Wu, S. B.; Liu, N. W.; Peng, C. Y.; Chan, T. H.; Hsu, C. F.; Wang, J. K.; Wang, Y. L. Adv. Mater. 2006, 18, 491-495.

(63) Tsai, K.-T.; Huang, Y.-R.; Lai, M.-Y.; Liu, C.-Y.; Wang, H.-H.; He, J.-H.; Wang, Y.-L. J. Nanosci. Nanotechnol. 2010, 10, 8293-8297. 